\title{
Defects in limb, craniofacial, and thymic development in Jagged 2 mutant mice
}

\author{
Rulang Jiang ${ }^{1,3}$ Yu Lan, ${ }^{1,3}$ Harry D. Chapman, ${ }^{1}$ Carrie Shawber, ${ }^{2}$ Christine R. Norton, ${ }^{1}$ \\ David V. Serreze, ${ }^{1}$ Gerry Weinmaster, ${ }^{2}$ and Thomas Gridley ${ }^{1,4}$ \\ ${ }^{1}$ The Jackson Laboratory, Bar Harbor, Maine 04609 USA; ${ }^{2}$ Department of Biological Chemistry, University of California, Los \\ Angeles (UCLA), The School of Medicine, Los Angeles, California 90024 USA
}

\begin{abstract}
The Notch signaling pathway is a conserved intercellular signaling mechanism that is essential for proper embryonic development in numerous metazoan organisms. We have examined the in vivo role of the JaggedR (Jag2) gene, which encodes a ligand for the Notch family of transmembrane receptors, by making a targeted mutation that removes a domain of the Jagged2 protein required for receptor interaction. Mice homozygous for this deletion die perinatally because of defects in crani ofacial morphogenesis. The mutant homozygotes exhibit cleft palate and fusion of the tongue with the pal atal shel ves. The mutant mice also exhibit syndactyly (digit fusions) of the fore- and hindlimbs. The apical ectodermal ridge (AER) of the limb buds of the mutant homozygotes is hyperplastic, and we observe an expanded domain of Fgf8 expression in the AER. In the foot plates of the mutant homozygotes, both Bmp2 and B $\mathrm{mp} 7$ expression and apoptotic interdigital cell death are reduced. Mutant homozygotes also display defects in thymic development, exhibiting altered thymic morphology and impaired differentiation of $\gamma \delta \delta$ lineage $T$ cells. These results demonstrate that Notch signaling mediated by Jag2 plays an essential role during limb, craniofacial, and thymic development in mice.
\end{abstract}

[Key Words: N otch signaling; Jagged2; Serrate2; limb development; cleft palate; T cell differentiation]

Received December 15, 1997; revised version accepted February 2, 1998.

The $\mathrm{N}$ otch signaling pathway is an evolutionarily conserved signaling mechanism, and mutations in its components disrupt cell fate specification and embryonic development in organisms as diverse as insects, nematodes, and mammals (for recent reviews, see A rtavanisTsakonas et al. 1995; Gridley 1997; Robey 1997; Weinmaster 1997). This signaling pathway was first identified and studied in Drosophila. The Notch gene of Drosophila encodes a large transmembrane receptor that, at the extracellular surface of a cell, interacts with membrane-bound ligands encoded by the Delta and Serrate genes. The signal induced by ligand binding is then transmitted at the intracellular surface in a process involving proteolysis of the receptor and interactions with several novel cytoplasmic and nuclear proteins (Fortini and Artavanis-T sakonas 1994; Jarriault et al. 1995; M atsuno et al. 1995; Kopan et al. 1996; Blaumueller et al. 1997; Pan and Rubin 1997). Genes homologous to members of the $\mathrm{N}$ otch signaling pathway have been cloned from numerous vertebrate organisms, and many have been shown to be essential for normal embryonic development. In humans, the importance of $\mathrm{N}$ otch signaling for growth and development is underscored by the finding that mutations in genes encoding components of the

\footnotetext{
${ }^{3}$ These authors contributed equally to this work. ${ }^{4}$ Corresponding author.

E-MAIL gridley@jax.org FAX (207) 288-6077.
}

$\mathrm{N}$ otch signaling pathway have been implicated in cancer and in two inherited disease syndromes (Ellisen et al. 1991; Joutel et al. 1996; Li et al. 1997; Oda et al. 1997).

Four genes encoding ligands for the $\mathrm{N}$ otch family of receptors have been cloned in mammals: Jagged1 (Jagl; Lindsell et al. 1995), Jagged2 (Jag2; Shawber et al. 1996; these genes are also referred to as Serratel and 2), Del talikel (DII1; Bettenhausen et al. 1995), and Delta-like3 (DII3; Dunwoodie et al. 1997). All of these N otch family ligands are transmembrane proteins that, in their extracellular domain, contain multiple EGF-like motifs as well as a second conserved motif termed the DSL domain (named after three invertebrate $\mathrm{N}$ otch ligands; Delta, Serrate, Lag-2). The DSL domain is required for interaction of ligands with $\mathrm{N}$ otch family receptors (Henderson et al. 1994; Muskavitch 1994). Two of these ligands, Jagged1 and Jagged2, have been shown to activate $\mathrm{N}$ otch1 in mammalian cells (Lindsell et al. 1995; Luo et al. 1997).

We have been studying the role of $\mathrm{N}$ otch signaling during embryonic development in mice. To study the biological role of the Jag2 gene, we made a targeted mutation that removes exons encoding the DSL domain of the Jagged2 protein. Mice homozygous for this deletion die at birth because of defects in craniofacial morphogenesis. The mutant mice have cleft palate, and dorsal portions of the tongue are fused to the unel evated palatal shelves. In addition, the mutant mice exhibit impaired 
differentiation of $\gamma \delta$ lineage $T$ cells and altered thymic morphology.

The Jag2 mutant homozygotes also exhibit syndactyly of the fore and hindlimbs. Previously, we mapped the Jag2 gene to distal Chromosome 12 (Lan et al. 1997), near two mutations that exhibit limb and/or craniofacial defects, syndactylism (sm; Grüneberg 1956) and legl ess (Igl ; Singh et al. 1991). Sidow et al. (1997) recently reported that the sm mutation is a missense mutation in the Jag2 gene. Our results suggest that sm is a hypomorphic allele of Jag2 because mice homozygous for our targeted DSL domain deletion exhibit completely penetrant perinatal lethality and syndactyly that is more severe than in sm homozygous mice, many of which survive to adulthood. These results demonstrate that $\mathrm{N}$ otch signaling mediated by Jag2 plays an essential role during limb, craniofacial, and thymic development in mice.

\section{Results}

Targeted disruption of the mouse Jag2 gene

Recently, we described the isolation of a gene, Jag2, which encodes a protein whose amino acid sequence and expression pattern during rat embryogenesis suggest that it functions as a ligand for the $\mathrm{N}$ otch family of receptors (Shawber et al. 1996). Mouse Jag2 cDN A and genomic clones were isolated by screening brain CDN A and genomic libraries (see $M$ aterials and $M$ ethods). To investigate the bi ological role of the Jag2 gene, we created a del etion allele by gene targeting. A Jag2 targeting vector was constructed that deleted genomic sequence encoding the DSL domain of the Jagged2 protein, which is required for interaction of ligands with $\mathrm{N}$ otch family receptors in both invertebrates (Henderson et al. 1994; Muskavitch 1994) and vertebrates (C. Lindsell and G. Weinmaster, unpubl.). Deletion of the DSL domain should create a null mutation in the Jag2 gene. We have named this mutant allele Jag2 ${ }^{\Delta \mathrm{DSL}}$ (Fig. 1A). The linearized targeting vector was electroporated into ES cells, and germ-line transmission of the Jag2 ${ }^{\Delta \mathrm{DSL}}$ mutant allele was obtained. Southern bl ot anal yses confirmed the expected structure of the transmitted allele, and also confirmed that the fragment containing the exon encoding the DSL domain was deleted in the transmitted Jag ${ }^{\Delta \mathrm{DSL}}$ mutant allele (Fig. 1B). Mice heterozygous for the Jag2 ${ }^{\Delta \mathrm{DSL}}$ mutant al lele appeared normal.

Jag2 ${ }^{\Delta \mathrm{DSL}}$ mutant mice die at birth with cleft palate

To examine whether mice homozygous for the Jag ${ }^{\Delta \mathrm{DSL}}$ mutation were viable, heterozygous $\mathrm{Fl}$ animals were intercrossed, and the genotypes of F2 progeny were determined two to three weeks after birth. No mice homozygous for the mutation were found, indicating that the Jag2 ${ }^{\Delta \mathrm{DSL}}$ mutation was lethal prior to this stage. To determine when the Jag2 ${ }^{\Delta \mathrm{DSL}}$ homozygotes were dying, embryos from timed matings were isol ated. This analysis revealed that Jag2 ${ }^{\Delta \mathrm{DSL}}$ homozygous mutants could complete embryogenesis, but died at or shortly after
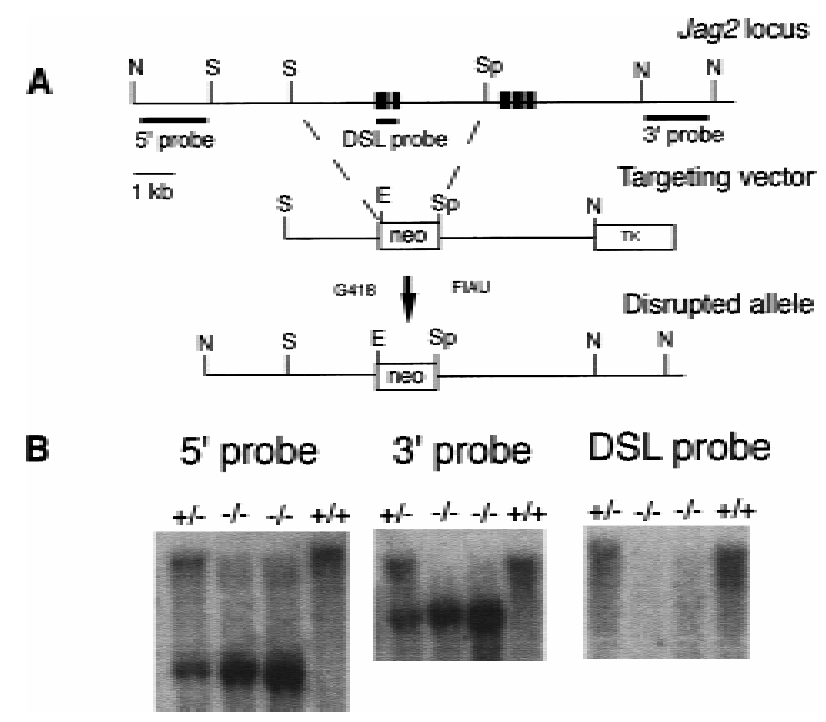

Figure 1. Targeted disruption of the mouse Jag2 gene. (A) Targeting scheme. The top line shows the genomic organization of a portion of the Jag2 gene. Exons are indicated by black boxes. Additional uncharacterized exons are present $3^{\prime}$ of the exons indicated. The middle line represents the structure of the targeting vector. A $5.0-\mathrm{kb}$ deletion was created that removes exons encoding the DSL domain and half of the first EGF repeat. Shown at the bottom is the predicted structure of the Jag2 locus following homologous recombination of the targeting vector. Probes used for Southern blot analysis are indicated. (E) EcoRI; (N) N otl; (S) Sacl; (Sp) Spel. (B) DN A isolated from embryos of the intercross of Jag2 ${ }^{+/ \Delta \mathrm{DSL}}$ heterozygous mice was digested with EcoRI, blotted, and hybridized with the indicated probe. Genotypes of progeny are indicated at the top of the lane. Lack of hybridization of the DSL domain probe to DNA of the Jag2 ${ }^{\Delta \mathrm{DSL}}$ homozygotes confirms that the fragment containing the exon encoding the DSL domain is del eted in the transmitted Jag2 ${ }^{\Delta \mathrm{DSL}}$ allele.

birth. Caesarean delivery at E18 of pups from heterozygous intercrosses indicated that the majority of the Jag2 ${ }^{\triangle D S L}$ homozygotes were unable to breathe, became cyanotic, and died within a few minutes. A few of the Jag2 ${ }^{\Delta \mathrm{DSL}}$ homozygotes were able to breathe, but all of these died within a few hours. A utopsy of these Jag $2^{\Delta \mathrm{DSL}}$ homozygous neonates reveal ed that they contai ned large amounts of air in the stomach and intestines.

Further examination of the Jag2 ${ }^{\Delta \mathrm{DSL}}$ mutant neonates reveal ed a bilateral cleft of the secondary palate (Fig. 2). During normal palatal morphogenesis, the palatal shel ves (consisting of the palatine and maxillary shelves) elevate and grow toward the midline of the embryo above the tongue. The shel ves then undergo an epithelial-mesenchymal transition to fuse and form the secondary palate, which ossifies and forms the roof of the oral cavity. In Jag2 ${ }^{\Delta \mathrm{DSL}}$ homozygous embryos, the palatal shel ves did not el evate, and the tongue became wedged between the shelves (Fig. 2A,B). In dorsal regions of the mutant embryos, the unel evated pal atal shelves had undergone an epithelial-mesenchymal transition and fused on each side with the posterior portion of the tongue (Fig. 

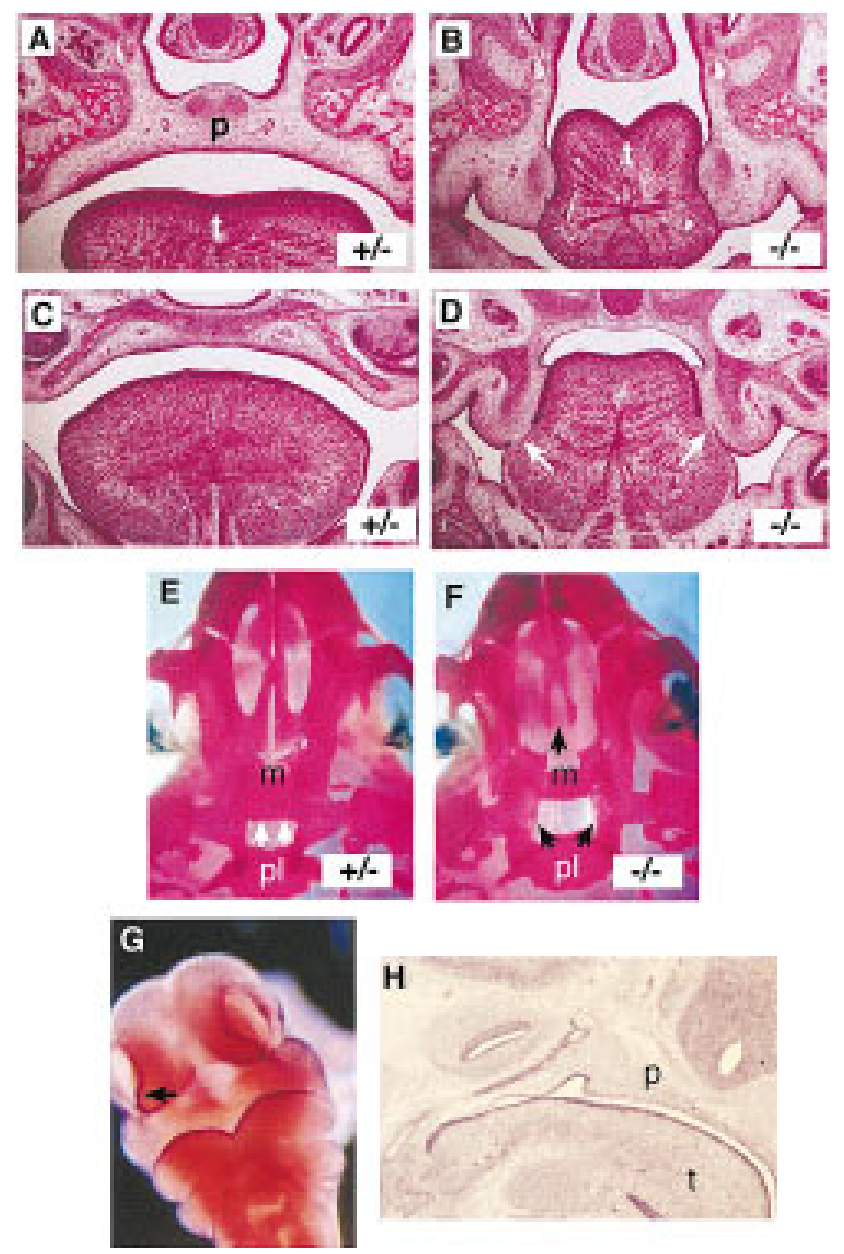

Figure 2. Cleft palate in Jag2 ${ }^{\Delta \mathrm{DSL}}$ homozygotes. (A-D) Frontal sections of $E 18$ embryos. Sections $A$ and $B$ are more ventral than sections $C$ and D. Genotypes are indicated in each panel. N ote in the Jag2 ${ }^{\Delta \mathrm{DSL}}$ homozygote fusion of the tongue with the unelevated palatal shelves (white arrows in D). (E,F) Ventral view of stained skeletal preparations of neonatal skulls. The dorsal extent of the palatine shelves is indicated with white arrows in the heterozygote $(E)$. In the Jag ${ }^{\Delta D S L}$ homozygote $(F)$, the palatine shelves have not grown toward and fused in the dorsal midline. The maxillary shelves are also more lateral in the Jag2 ${ }^{\Delta \mathrm{DSL}}$ homozygote. $(\mathrm{G}, \mathrm{H})$ Jag2 RN A expression in wild-type mouse embryos. In the head of a E10.5 mouse embryo (G), Jag2 is expressed in the epithelial cell layer of the branchial arches and the area surrounding the nasal pits. $(\mathrm{H})$ Sagittal section of an E12.5 mouse embryo reveal ed high levels of Jag2 expression in the epithelium and muscles of the tongue, and epithelium of the palate and nasal pharynx. (m) Maxillary shelf; $(p)$ palate; ( $p l)$ palatine shelf; (t) tongue.

$2 \mathrm{C}, \mathrm{D})$. Examination of stained skel etal preparations confirmed that the maxillary and palatine shelves were absent in the Jag2 ${ }^{\Delta \mathrm{DSL}}$ mutant neonates (Fig. $2 \mathrm{E}, \mathrm{F}$ ). The fusi on of the unel evated palatal shelves with the tongue prevents proper formation of the oral cavity, and is the apparent cause of the breathing difficulties and perinatal lethality of the Jag2 ${ }^{\Delta \mathrm{DSL}}$ homozygous neonates. To determine if the palatal clefting in the Jag $2^{\Delta \mathrm{DSL}}$ homozy- gotes correlated with a domain of Jag2 expression, we anal yzed crani ofacial expression of Jag2 during embryogenesis in mice. High levels of expression were observed in the epithelial cell layer of the branchial arches and the area surrounding the nasal pits (Fig. 2G). Jag2 expression in craniofacial epithelia, including nasal, tongue, and palatal epithelia, was maintained throughout embryogenesis (Fig. $2 \mathrm{H}$ ). A very similar pattern of Jag2 expression during mouse embryogenesis was recently reported by another group (Luo et al. 1997).

Jag2 ${ }^{\mathrm{DSS}}$ mutant mice have syndactyl ous limbs and a hyperplastic apical ectodermal ridge

In the limb bud of wild-type embryos at E9.5, prior to formation of the apical ectodermal ridge (AER), Jag2 is expressed throughout the ectoderm of the developing limb bud (Fig. 3A). Once the AER forms at E10.5, Jag2 expression in the limb becomes restricted to the AER (Fig. 3B). Importantly, expression of the Notch1 gene has been observed in the AER in both chicks and rats (Myat et al. 1996; Shawber et al. 1996; Rodriguez-Esteban et al . 1997). Whole mount in situ hybridization of wild-type mouse embryos at E10.5 also reveal ed weak expression of Notch1 in the AER (Fig. 3C).

Examination of the limbs of the Jag2 $2^{\Delta \mathrm{DSL}}$ homozygous neonates revealed that they exhibited syndactyly (digit fusions) of both the fore and hindlimbs (Fig. 4B). The syndactyly affected digits 2,3 , and 4 , and in many instances appeared to involve soft tissue fusions, al though skel etal staining revealed that 5 of 13 mutant skel etons examined had primary chondrogenic or secondary osseous fusions of the distal phalanges, with the hindfeet more severely affected (Fig. 4C-F). Several of the mutant skeletons also exhibited splitting of the terminal phaIanx of digit 2 of the hindfeet (Fig. 4E,F).

Histological analysis revealed that the AER of Jag2 ${ }^{\mathrm{DSL}}$ homozygous embryos was hyperplastic. Whereas in wild-type and heterozygous littermates the AER was a relatively thin epithelial thickening at the
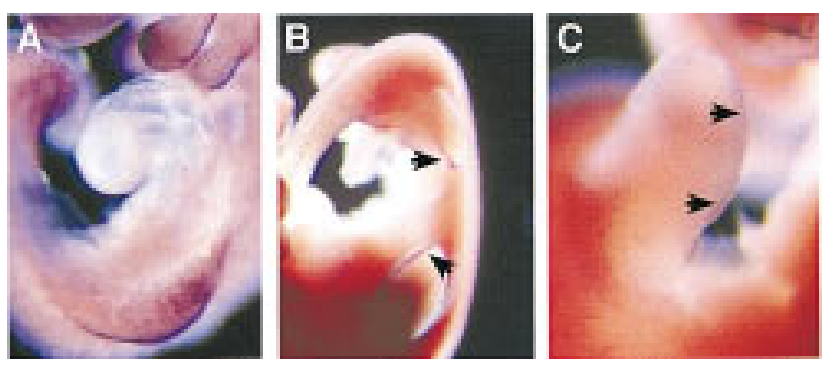

Figure 3. Expression of Jag2 and Notch1 in limb buds of wildtype embryos. Whole mount in situ hybridization of mouse embryos at E9.5 and E10.5. (A) Prior to formation of the AER at E9.5, Jag2 is expressed throughout the limb ectoderm. (B) After AER formation at E10.5, Jag2 expression becomes restricted to the AER (arrows). (C) Low levels of Notch1 expression are also detected in the AER at E10.5 (arrows). 

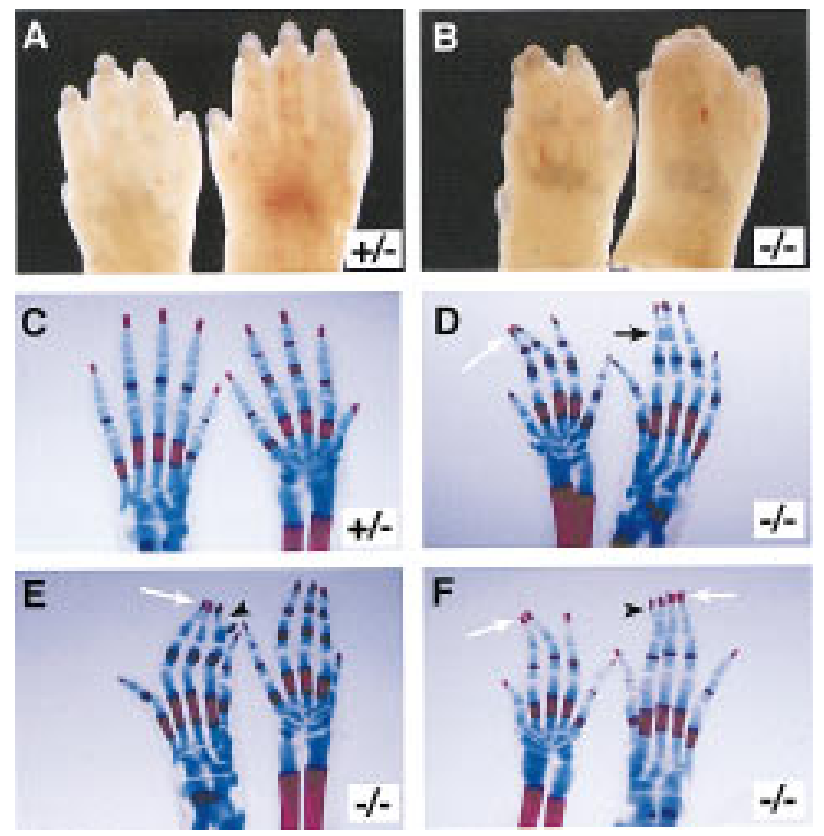

Figure 4. Limb defects in Jag2 $2^{\Delta \mathrm{DSL}}$ homozygotes. $(\mathrm{A}, \mathrm{B})$ Feet of neonatal mice. A forefoot (left) and hindfoot (right) is shown in each panel. Jag2 ${ }^{\Delta \mathrm{DSL}}$ homozygous neonates (B) exhibit syndactyly of both fore and hindlimbs, although the hindlimbs are more severely affected. (C-F) Stained skeletal preparations of neonatal limbs of a heterozygous (C) and three Jag2 ${ }^{\Delta \mathrm{DSL}}$ homozygous mice (D-F). Both a fore- and a hindfoot are shown in each panel. The forefoot is on the right in $\mathrm{C}$ and $\mathrm{E}$, and on the left in $\mathrm{D}$ and $\mathrm{F}$. The homozygotes display several defects affecting distal phalanges, including secondary osseous fusions of both foreand hindfeet (white arrows in D-F), primary chondrogenic fusions (black arrow in D), and terminal splitting of a distal phalanx (arrowheads in E,F).

distal end of the limb bud (Fig. $5 \mathrm{~A}$ ), in the Jag2 ${ }^{\Delta \mathrm{DSL}}$ homozygotes the AER was larger and protruded into the underlying mesenchyme of the progress zone (Fig. 5B). Hyperplasia of the AER was also revealed by whole mount in situ hybridization by use of marker genes expressed in the AER. These whole mount in situ studies also revealed that the shape of the foot plate differed between the Jag2 ${ }^{\Delta \mathrm{DSL}}$ homozygous embryos and their wild-type and heterozygous littermates. The foot plates of the Jag2 ${ }^{\Delta \mathrm{DSL}}$ homozygotes were rounder than those of their littermates, and did not exhibit the same degree of interdigital cl efting as their littermates (see Figs. 5-7).

Fgf8 (fibroblast growth factor 8) is both an excellent marker for the $A E \bar{R}$ and is one of the molecules required for AER function ( $\mathrm{N}$ iswander and $\mathrm{M}$ artin 1993; Fallon et al. 1994; Laufer et al. 1994; M ahmood et al. 1995; Crossley et al. 1996; Vogel et al. 1996). We examined Fgf8 expression in the limb buds of Jag2 ${ }^{\Delta \mathrm{DSL}}$ homozygotes and littermate controls from E9.5 to E12.5. At E9.5 (prior to AER formation), Fgf8 was expressed as a broad stripe at the dorsal/ventral boundary of the forelimb bud and throughout the ectoderm of the hindlimb bud. This pattern of Fgf8 expression is the same in both Jag2 ${ }^{\Delta \mathrm{DSL}}$ homozygotes and littermate controls (Fig. 5C,D). At E10, the AER forms first on the forel imb bud and then on the hindlimb bud. When examined at E10.5, the Fgf8 expression domain in the newly formed AER of the hindlimb bud was the same in both Jag2 $2^{\mathrm{DSL}}$ homozygotes and littermate controls. However, the Fgf8 expression domain is expanded in some of the mutant forelimb buds (Fig. 5E,F). At E11.5, all six mutant embryos examined exhibited expanded domains of Fgf8 expression in both fore and hindlimb buds (Fig. 5G,H). By E12.5, the Fgf8

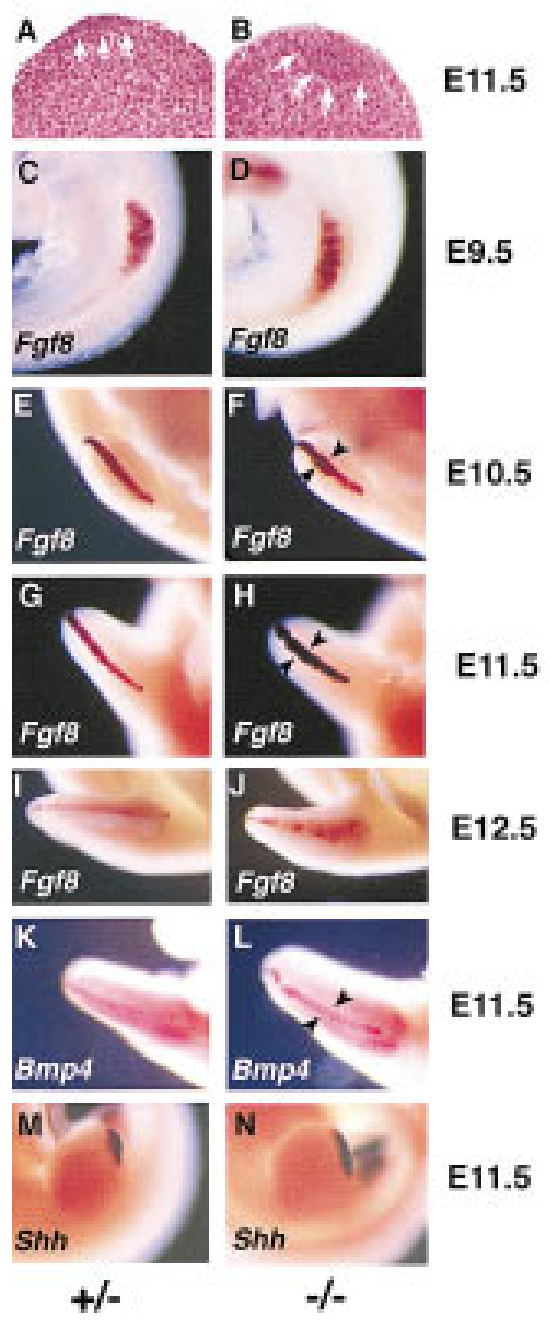

Figure 5. Jag2 $2^{\Delta \mathrm{DSL}}$ homozygotes have a hyperplastic AER and exhibit altered marker gene expression. (A,B) Histological analysis of forelimb buds of Jag2 ${ }^{\Delta \mathrm{DSL}}$ homozygous mutant embryo (B) and littermate control (A) at E11.5. The extent of the AER is indicated by the white arrows. (C-J) Time course of Fgf8 expression in the limb bud. (C,D) At E9.5, Fgf8 is expressed in a broad band in the forelimb bud ectoderm of both the Jag $2^{\Delta \mathrm{DSL}}$ homozygote and the littermate control. (D,E) At E10.5, the Fgf8 expression domain in the AER of the forelimb is broader in the some of the Jag $2^{\triangle \mathrm{DSL}}$ homozygotes than in wild-type or heterozygous littermates. $(\mathrm{G}, \mathrm{H})$ At E11.5, the Fgf8 expression domain is expanded in the AER of both fore and hindlimbs of all Jag2 $2^{\mathrm{DSL}}$ homozygotes. $(\mathrm{I}, \mathrm{J})$ At E12.5, the Fgf8 expression re mains broader in the mutants, and is also more irregular along the anterior margin of the limb bud. $(K, L) B m p 4$ expression at E11.5. (M,N) Shh expression at E11.5. 
Jiang et al.
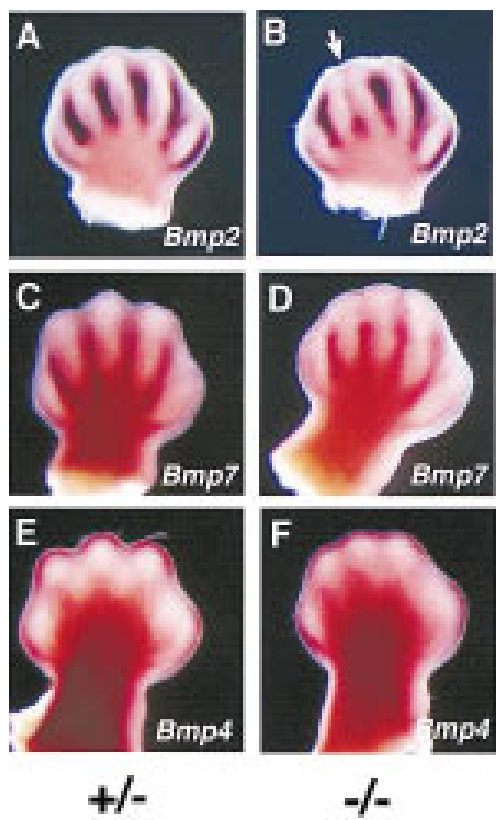

Figure 6. Expression of $\mathrm{Bmp2}$ and $\mathrm{Bmp7}$ is reduced in limbs of Jag2 ${ }^{\Delta \mathrm{DSL}}$ homozygotes. (A,B) Bmp2 expression. Bmp2 expression is reduced in Jag2 ${ }^{\triangle \mathrm{DSL}}$ homozygous mutants between the devel oping digits 2 and 3 (white arrow). (C,D) Bmp7 expression. $\mathrm{Bmp7}$ expression is reduced in distal regions of the interdigital mesenchyme in the Jag2 ${ }^{\Delta \mathrm{DSL}}$ mutants. (E,F) Bmp4 expression. Bmp4 expression in distal mesenchyme is unaffected in the Jag2 ${ }^{\Delta \mathrm{DSL}}$ mutants. N ote the al tered morphol ogy of the foot plate in the Jag2 ${ }^{\triangle \mathrm{DSL}}$ homozygous mutants $(B, D, F)$. All embryos shown are at E13.5.

expression domain in the Jag2 ${ }^{\Delta \mathrm{DSL}}$ homozygotes was still broader but was also more irregular, particularly along the anterior margin of the limb bud, than in control littermates (Fig. 5l,J).

We al so examined expression of other genes expressed in the AER to determine whether they would show expanded expression domains similar to Fgf8. We examined expression of the genes encoding the bone morphogenetic proteins Bmp2, Bmp4, and Bmp7. At E10.5, all of these genes were expressed in the AER, and no differences in their domains of expression were detected between Jag2 ${ }^{\Delta \mathrm{DSL}}$ homozygotes and littermate controls (data not shown). Other sites of expression of these genes in the limb bud (e.g., expression of Bmp2 in the zone of polarizing activity and expression of Bmp7 in the anterior and posterior mesenchyme) were also unchanged in the mutants. By E11.5, expression of both Bmp2 and Bmp7 was downregulated in the AER, whereas Bmp4 was still expressed in the AER. This Bmp4 expression domain is expanded in the Jag2 ${ }^{\Delta \mathrm{DSL}}$ homozygotes (Fig. $5 \mathrm{~K}, \mathrm{~L})$. These data are consistent with the time course of the AER hypertrophy that we had observed histologically and by Fgf8 expression.

Previous work has demonstrated a positive feedback loop in the developing limb between the AER and the zone of polarizing activity (ZPA), the organizing center responsible for anterior-posterior patterning of the limb (Laufer et al. 1994; N iswander et al. 1994; for review, see Johnson and Tabin 1997). The ZPA exerts its activity through the production of the morphogen Sonic hedge hog (Shh). Because of this positive feedback loop between the AER and the ZPA, one consequence of a hyperplastic AER might be an expansion of the ZPA. Therefore, we examined Shh expression in limb buds of Jag2 ${ }^{\triangle \mathrm{DSL}}$ homozygotes and littermate controls, and found that the domain of Shh expression was expanded in the Jag $2^{\Delta \mathrm{DSL}}$ homozygous mutants (Fig. 5M,N).

It is apparent from the histological analyses and marker gene expression data described above that the AER forms normally in the Jag2 ${ }^{\Delta \mathrm{DSL}}$ homozygous mutants and becomes hyperplastic between E10.5 and E11.5. We examined whether there might be decreased programmed cell death in the AER of the Jag2 ${ }^{\triangle \mathrm{DSL}}$ homozygous mutants by analyzing in situ detection of terminal transferase-catalyzed digoxigenin-dUTP labeling (TUN EL assay) on sections of E10.5 limb buds. Very few apoptotic cells were detected in the AER, and the numbers of labeled cells did not differ significantly between Jag2 ${ }^{\Delta \mathrm{DSL}}$ homozygotes and littermate controls (data not shown).

Jag2 ${ }^{\Delta \mathrm{DSL}}$ mutant mice exhibit reduced Bmp2 and Bmp7 expression and decreased interdigital cell death

In amniote vertebrates, the formation of di gits occurs by the el imination of mesenchymal cells in the interdigital regions through programmed cell death. Apoptotic cell
Figure 7. Visualization of interdigital cell death by Nile Blue Sulphate vital staining. Limb buds were isolated at E13.5. Plantar (ventral) apects of hindfeet are shown. Apoptotic cells that stain blue with Nile Blue Sulphate are observed between all forming digits of wild-type and heterozygous littermates, as well as in the anterior (a) and posterior ( $p$ ) necrotic zones (A) In Jag2 ${ }^{\Delta \mathrm{DSL}}$ homozygotes $(B, C)$, the numbers of staining cells are greatly reduced in the regions where digits 2,3 , and 4 would normally form. There is no apparent reduction of staining cells in the region between digits 1 and 2, and in the anterior and posterior necrotic zones.
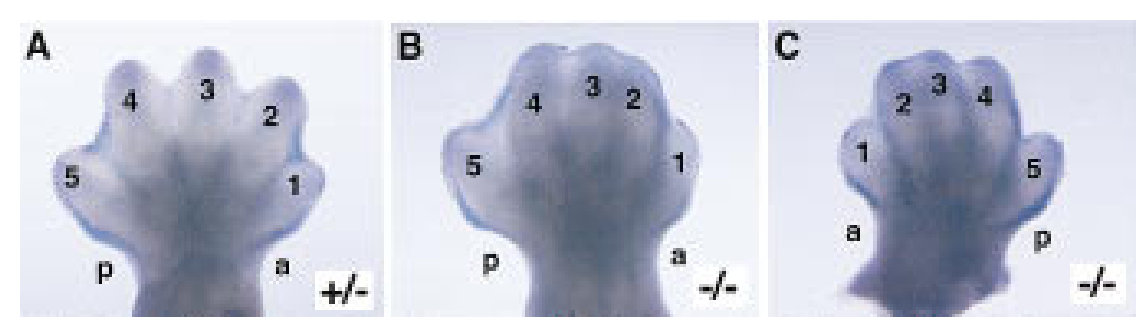
death in the interdigital regions is regulated by BM Pmediated signaling (M acias et al. 1996, 1997; Y okouchi et al . 1996; Zou and N iswander 1996). Therefore, we examined Jag2 ${ }^{\Delta \mathrm{DSL}}$ homozygotes for expression of $\mathrm{Bmp2}$, Bmp4, and Bmp7 at later stages than were used to examine hypertrophy of the AER. At E13.5 in wild-type embryos, Bmp2 was strongly expressed in the interdigital mesenchyme and al ong the margins of the foot plate in the anterior and posterior necrotic zones (Fig. 6A). In the Jag2 ${ }^{\Delta \mathrm{DSL}}$ homozygotes, expression of $\mathrm{Bmp2}$ was reduced between developing digits 2 and 3 (the digits most severely affected by the syndactylous phenotype; Fig. 6B). Bmp7 was also expressed in the interdigital mesenchyme of wild-type embryos at E13.5, although it was not expressed as strongly as Bmp2 (Fig. 6C). In the Jag2 ${ }^{\Delta \mathrm{DSL}}$ homozygotes, Bmp7 expression was reduced, particularly in the distal portions of the interdigital region (Fig. 6D). Bmp4 was expressed at E13.5 in the distal mesenchyme of the limb bud (Fig. 6E; also see Dunn et al. 1997). Bmp4 expression was unaffected in the Jag2 ${ }^{\Delta \mathrm{DSL}}$ homozygotes (Fig. $6 \mathrm{~F}$ ).

We also di rectly visual ized apoptotic cells in the limb bud by vital staining with $\mathrm{N}$ ile Blue Sulphate ( $\mathrm{M}$ ori et al . 1995). This analysis revealed a reduction of interdigital cell death in the mutants in the region where digits 2,3 , and 4 were forming, whereas the region between digits 1 and 2 and the anterior and posterior necrotic zones (in which anterior and posterior marginal mesoderm of the limb bud is removed) were unaffected (Fig. 7A-C). Thus, the syndactyly of the Jag $2^{\Delta \mathrm{DSL}}$ homozygotes is accompanied by hyperplasia of the AER, altered morphology of the foot plate, an expanded domain of Fgf8 expression, and reductions in expression of Bmp2 and Bmp7, and a reduction of interdigital cell death.

Jag2 $2^{\Delta \mathrm{DSL}}$ mutant mice exhibit impaired differentiation of $\gamma \delta \mathrm{T}$ cells

A nother major site of Jag2 expression during embryogenesis is the thymus (Shawber et al. 1996; Luo et al. 1997). Both Jag2 and Notch1 are coexpressed in the fetal thymus (Luo et al. 1997), suggesting a role for the $\mathrm{N}$ otch signaling pathway during thymic development. Indeed, Robey and colleagues have shown previously that perturbations in $\mathrm{N}$ otch signaling mediated by the Notch1 gene can affect the development of particular T cell lineages (Robey et al. 1996; Washburn et al. 1997). To examine whether loss of Jag2 gene function leads to similar alterations in T cell development, we performed flow cytometric analyses on thymocytes isolated from Jag2 ${ }^{\Delta \mathrm{DSL}}$ homozygous mutant embryos and control littermates at E18 ( 1 day prior to birth).

The vast majority ( $>95 \%$ ) of mature murine T cells express either the CD4 or CD8 marker and utilize antigen-specific $T$ cell receptor (TCR) molecules consisting of an $\alpha$ and $\beta$ chain heterodimer ( $\alpha \beta$ lineage $T$ cells). During their course of differentiation in the thymus, $\mathrm{TCR} \alpha \beta$ expression is first observed in $\mathrm{CD} 4^{+} / \mathrm{CD} 8^{+}$ (double positive) $\mathrm{T}$ cells. However, a subset of murine $\mathrm{T}$ cells utilize an antigen-specific TCR molecule com- prised of a $\gamma \delta$ chain heterodimer ( $\gamma \delta$ lineage T cells). In the thymus, TCR $\gamma \delta$ expression is generally restricted to a subset of $\mathrm{CD}^{-} / \mathrm{CD}^{-}$(double negative) cells whose appearance precedes that of double positive cells. In fetal thymuses from Jag2 ${ }^{\Delta \mathrm{DSL}}$ homozygotes, the percentage of total $\gamma \delta \mathrm{T}$ cells, as well as those among the CD4-/CD8 ${ }^{-}$ double negative subset, was approximately one-half that observed in wild-type and heterozygous littermate controls (representative data shown in Fig. 8A,B; data from all embryos anal yzed is summarized in Table 1). In contrast, fetal thymuses from Jag ${ }^{\Delta \mathrm{DSL}}$ homozygotes and littermate controls did not differ in the proportion of CD4/ CD8 double positive cells that expressed rearranged TCR $\alpha \beta$ molecules. Similarly, fetal thymuses from Jag2 ${ }^{\Delta \mathrm{DSL}}$ homozygotes and littermate controls did not differ in proportions of total double negative, double positive, CD4 single positive, or CD8 single positive cells.

Histological analyses al so revealed alterations in thymic morphology in the Jag2 ${ }^{\Delta \mathrm{DSL}}$ homozygous embryos. Examination of hematoxylin and eosin stained sections of fetal thymuses from wild-type and Jag2 ${ }^{\Delta \mathrm{DSL}}$ heterozygous littermate controls revealed darker-stained cortical regions and multiple lighter-stained medullary regions (Fig. 8C). In sections of fetal thymuses from Jag $2^{\Delta \mathrm{DSL}}$ homozygotes, the amount and number of the lighterstaining medullary regions appeared reduced (Fig. 8D,E). Thus, Jag2 ${ }^{\Delta \mathrm{DSL}}$ homozygous mutant embryos exhibit both impaired differentiation of $\gamma \delta$ lineage $T$ cells and altered thymic morphology.

\section{Discussion}

To determinethe biol ogical role of the Jag 2 gene in mice, we constructed and anal yzed animals homozygous for a deletion that removed the exons encoding the DSL domain of the Jagged2 protein. The phenotype of the Jag2 ${ }^{\mathrm{DSL}}$ homozygotes demonstrates that Jag2-mediated $\mathrm{N}$ otch signaling is essential for proper craniofacial morphogenesis, as well as for proper thymic and limb development. These phenotypes correlate well with domains of Jag2 expression in the tongue and palatal epithelium, in the embryonic thymus, and in the AER of the limb bud.

\section{Cleft palate in Jag2 ${ }^{\Delta \mathrm{DSL}}$ mutant mice}

Cleft palate is among the most common birth defects in humans, and is also commonly observed in both spontaneous and targeted mouse mutants and in mouse embryos exposed to teratogenic agents during embryogenesis (e.g., Lohnes et al. 1994; Satokata and Maas 1994; Kaartinen et al. 1995; Proetzel et al. 1995; Orioli et al. 1996; Mo et al. 1997, and references therein). This sug gests that disruptions in multiple developmental pathways can lead to palatal clefting. Much less commonly observed, however, is completely penetrant cleft pal ate, which we have seen in the Jag $2^{\Delta \mathrm{DSL}}$ homozygous mu- 
Figure 8. $\operatorname{Jag}^{\Delta \mathrm{DSL}}$ homozygotes exhibit impaired differentiation of $y \delta T$ cells and altered thymic morphology. (A,B) FACS profiles of fetal thymocytes from a representative control littermate (A) and a Jag2 ${ }^{\Delta \mathrm{DSL}}$ homozygous mutant (B) assessed for CD4 vs. CD8 expression, proportion of $\mathrm{TCR} \alpha \beta^{+}$cells in the $\mathrm{CD} 4^{+} \mathrm{CD} 8^{+}$population, and $T C R \gamma \delta^{+}$cells in the CD4CD ${ }^{-}$ population. Broken lines denote the background staining levels that were used to establish gates for respectively assessing labeling of $\mathrm{CD}^{+}{ }^{+} \mathrm{CD} 8^{+}$and $\mathrm{CD} 4 \mathrm{CD}^{-}$ cells by phycoerythrin-conjugated TCR $\alpha \beta$ - or $\gamma \delta$-specific monoclonal antibodies. Annotated numbers denote the percent positive cells of the indicated phenotype. (C-E) A t tered morphology of the fetal thymus in Jag2 ${ }^{\Delta \mathrm{DSL}}$ homozygotes at E18. (C) Thymus section from heterozygous littermate. $(D, E)$ Thymus sections from two Jag2 ${ }^{\Delta \mathrm{DSL}}$ homozygotes. In the heterozygote, both darker-stained cortical regions and multiple lighter-stained medullary regions (arrows) can be observed. In the Jag2 ${ }^{\Delta \mathrm{DSL}}$ homozygotes, both the number and the size of the developing medullary regions are reduced.

\section{TCR $\alpha \beta$ in \\ $\mathrm{CD} 4+8+$ \\ TCR $\gamma \delta$ in \\ CD4-8-}
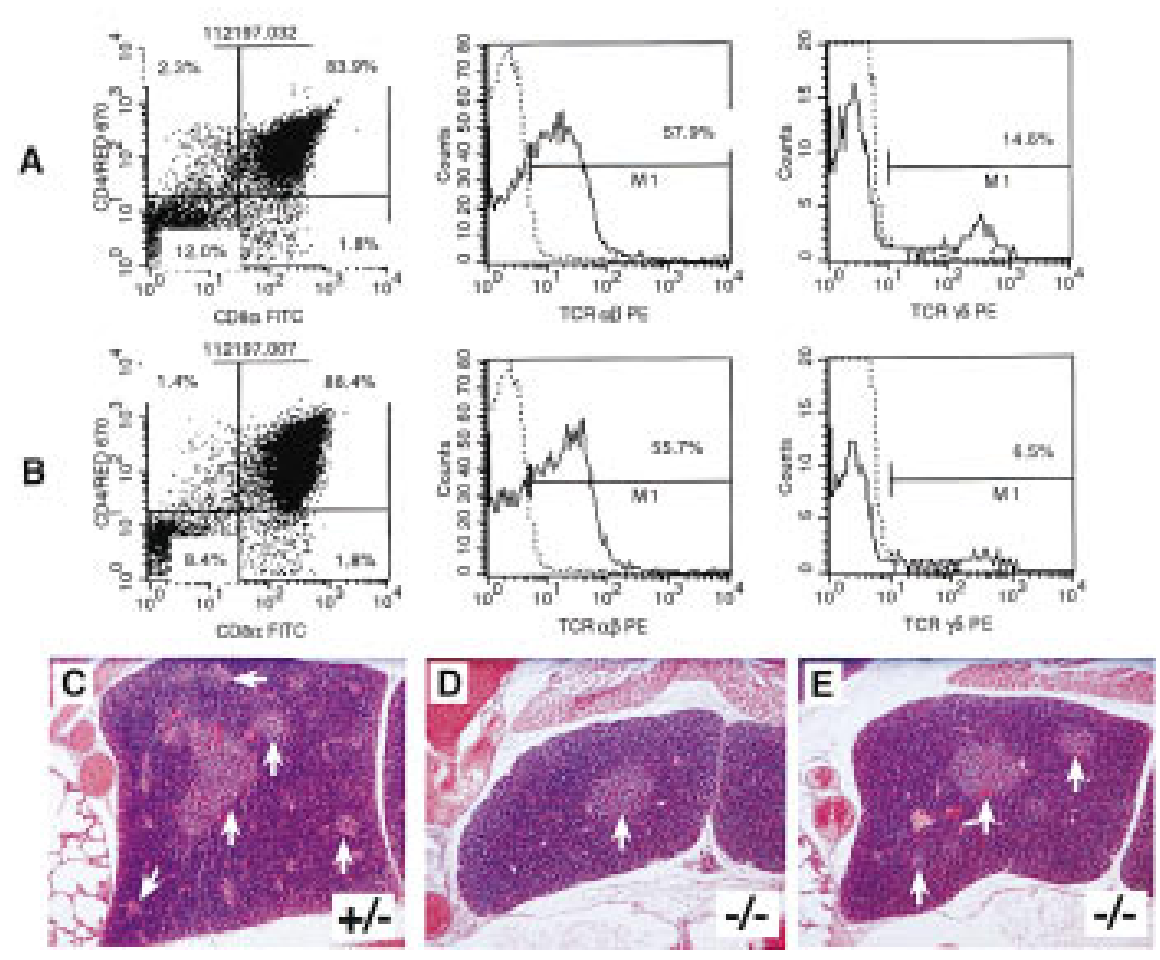

tants. This suggests that the Jag2 gene may play a highly specific role during palatal morphogenesis, and that the palatal clefting observed in the Jag2 ${ }^{\Delta \mathrm{DSL}}$ homozygotes is not a secondary defect.

During normal palatal morphogenesis, the palatal shelves must elevate, then grow toward the midline of the embryo above the tongue. When the two palatal shelves from either side of the embryo come into proximity, they undergo an epithelial-mesenchymal transition to fuse and form the secondary palate, which ossifies and forms the roof of the oral cavity (Ferguson 1988). Mutations have been found that block different stages of this process. In some mutants that exhibit cleft palate, the shelves elevate and come into proximity, but are unable to undergo the epithelial-mesenchymal transformation and fail to fuse al ong the midline of the embryo (e.g., Kaartinen et al. 1995; Proetzel et al. 1995). In other mutants, the palatal shel ves elevate but do not grow toward the midline of the embryo, possibly because of a deficiency of craniofacial mesenchyme (e.g., Satokata and $M$ aas 1994). The type of cleft palate exhibited in the Jag2 ${ }^{\mathrm{DSS}}$ homozygotes represents a third category, in which the palatal shelves fail to el evate. Lack of palatal shelf elevation is also observed in mouse embryos homozygous for a particular deletion in the piebald complex (O'Brien et al. 1996). However, the fusi ons between the unelevated palatal shelves and the tongue that we observe in the Jag2 ${ }^{\Delta \mathrm{DSL}}$ homozygotes appears to be quite unusual.
Thymic development in Jag2 ${ }^{\Delta \mathrm{DSL}}$ mutant mice

Alterations in Notch signaling mediated by the Notch1 gene have been shown previously to affect development

Table 1. Summary of flow cytometry analyses of fetal thymocytes from Jag2 ${ }^{\Delta \mathrm{DSL}}$ mutant embryos and littermate controls

\begin{tabular}{|c|c|c|}
\hline \multirow{2}{*}{$\begin{array}{l}\text { Thymic subset } \\
\text { analyzed }\end{array}$} & \multicolumn{2}{|c|}{ Jag2 genotype } \\
\hline & $H+, H-$ & $-1-$ \\
\hline $\mathrm{CD}^{-} \mathrm{CD}^{-}$ & $7.9 \pm 0.9(n=14)$ & $8.0 \pm 1.1(n=11)$ \\
\hline $\mathrm{CD}^{+}{ }^{+} \mathrm{CD} 8^{+}$ & $83.6 \pm 1.2(n=14)$ & $85.6 \pm 1.4(n=11)$ \\
\hline $\mathrm{CD}^{+}{ }^{+} \mathrm{CD} 8^{-}$ & $3.2 \pm 0.3(n=14)$ & $3.3 \pm 0.3(n=11)$ \\
\hline CD4-CD8 ${ }^{+}$ & $4.3 \pm 0.9(n=14)$ & $3.3 \pm 0.9(n=11)$ \\
\hline TCR $\alpha \beta^{+}$among & & \\
\hline $\begin{array}{l}\text { CD } 4^{+} \text {CD } 8^{+} \text {cells } \\
\text { TCR } \gamma \delta^{+} \text {among total }\end{array}$ & $52.1 \pm 1.0(n=19)$ & $50.5 \pm 1.1(n=15)$ \\
\hline $\begin{array}{l}\text { thymocytes } \\
\text { TCR } \delta^{+} \text {among }\end{array}$ & $2.6 \pm 0.1(n=19)$ & $1.3 \pm 0.1(n=15)^{a}$ \\
\hline CD4-CD8 ${ }^{-}$cells & $19.6 \pm 1.3(n=19)$ & $11.8 \pm 1.0(n=15)^{a}$ \\
\hline
\end{tabular}

Total cells isolated per thymic lobe did not differ between mutants and controls. No differences were noted between $t+$ and $H$-littermate controls, so data from these two genotypes were combined. Data are presented as the mean $\% \pm$ S.E.M. of cells expressing the indicated differentiation markers. Numbers of embryos tested are given in parentheses.

aSignificantly less ( $P<0.001$, Student's t-test) than in $t+$ and + -littermate controls. 
of particular T cell lineages (Robey et al. 1996; Washburn et al. 1997). The Jag2 gene is expressed at high levels in the embryonic thymus (Shawber et al. 1996; Luo et al. 1997), which suggests that Jagged 2 protein may function as the ligand for the $\mathrm{N}$ otch1 protein during thymic development. Jag2 ${ }^{\Delta \mathrm{DSL}}$ homozygous mutant embryos at E18 exhibit both altered thymic morphology and a reduction in the number of $\gamma \delta \mathrm{T}$ cells. These results demonstrate that $\mathrm{N}$ otch signaling mediated through the Jag2 gene is essential for normal thymic development and for the differentiation of normal numbers of $\gamma \delta \mathrm{T}$ cells.

It is informative to compare our experiments with those of Robey and colleagues (Washburn et al. 1997). In the experiments described in this report, we directly analyzed thymocytes of Jag2 ${ }^{\Delta \mathrm{DSL}}$ homozygotes and littermate controls just before birth (we could not analyze them after birth, because of the completely penetrant neonatal lethality associated with the craniofacial defects of the Jag2 ${ }^{\mathrm{DSS}}$ homozygotes). However, thymocytes from Notch1-deficient mice cannot be analyzed directly because homozygous Notch1-deficient embryos die during embryogenesis, prior to differentiation of the thymus (Swiatek et al. 1994; Conlon et al . 1995). Therefore, Washburn et al . (1997) examined T cell differentiation in irradiated ragl mutant mice reconstituted with a mixture of equal portions of fetal liver or bone marrow cells from $\mathrm{Notch}^{+++}$and $\mathrm{Notch}^{+1-}$ donor mice (Notch1 ${ }^{-1-}$ stem cells could not be examined, because Notch1-deficient embryos die prior to differentiation of fetal liver cells). Under these conditions, they found that $\mathrm{T}$ cells derived from $\mathrm{N}$ otch $1^{+/-}$stem cells are less likely than $\mathrm{T}$ cells derived from $\mathrm{N}$ otch $1^{+/+}$stem cells to differentiate as $\alpha \beta$ T cells. This effect was observed only in chimeras reconstituted with a mixture of $\mathrm{Notch} 1^{++}$and $\mathrm{N}$ otch $1^{+-}$stem cells. In either intact $\mathrm{Notch} 1^{+/-}$mice, or in same genotype chimeras (i.e., chimeras reconstituted with only $\mathrm{Notch} 1^{++}$or $\mathrm{Notch} 1^{+-}$stem cells, but not a mixture of the two), no effect on differentiation of $\alpha \beta T$ cells was observed. Washburn et al. (1997) also found that $\mathrm{T}$ cells derived from $\mathrm{Notch} 1^{+1-}$ stem cells are less likely than $\mathrm{T}$ cells derived from $\mathrm{Notch} 1^{++}$stem cells to differentiate as $\gamma \delta \mathrm{T}$ cells, and observed that the ratio of $\gamma \delta$ to $\alpha \beta$ T cells was higher in T cells derived from Notch $1^{+-}$stem cells. Therefore, they suggested that reduced $\mathrm{N}$ otch signal ing mediated by the N otch 1 gene favored differentiation of the $\gamma \delta$ lineage over the $\alpha \beta$ lineage.

Our analysis of $\mathrm{T}$ cell differentiation in Jag2 ${ }^{\Delta \mathrm{DSL}}$ homozygous mutant embryos provides further evidence that perturbations of the $\mathrm{N}$ otch signaling pathway can influence the differentiation of particular T cell subsets. However, in the Jag2 ${ }^{\Delta \mathrm{DSL}}$ homozygotes, only differentiation of $\gamma \delta$ lineage T cells is impaired, whereas differentiation of $\alpha \beta$ T cells is unaffected. This may suggest that another ligand interacts with the $\mathrm{N}$ otch 1 protein during differentiation of the $\alpha \beta$ T cell lineage. A more detailed analysis of the role of the Jag 2 gene during $T$ cell differentiation will require chimera studies similar to those performed to analyze Notch1 function (Washburn et al. 1997).
Limb defects in mice mutant for two different Jag2 mutant alleles

Previously, we mapped the Jag2 gene to distal Chromosome 12 (Lan et al. 1997), near the spontaneous mouse mutation sm. Sidow et al. (1997) have shown recently that the sm mutation is a missense mutation in the Jag2 gene that causes a glycine to serine substitution in the first EGF repeat. Therefore, we will refer to the mutant allele present in the sm mutants as the Jag $2^{\text {sm }}$ al lele. The Jag2 ${ }^{\text {sm }}$ mutation arose spontaneously in the A/Fa inbred strain (Grüneberg 1956). In Jag2 ${ }^{\text {sm }}$ homozygotes, digits of the forefeet were joined by soft tissues only, whereas fusions of cartilage or bone were often observed on the hindfeet. Considerable postnatal mortal ity of Jag2 ${ }^{\text {sm }}$ homozygotes was also observed, although the cause of this lethality was not studied further (Grüneberg 1956).

Morphological and histological examination of the limb buds of Jag2 ${ }^{\text {sm }}$ homozygotes indicates that the AER is hyperplastic (Grüneberg 1960; Milaire 1967; Sidow et al. 1997). We show here that the AER of the Jag $2^{\Delta \mathrm{DSL}}$ homozygotes is al so hyperplastic (Fig. 5A,B). The authors of these earlier studies suggested that the syndactyly of the Jag ${ }^{\text {sm }}$ homozygotes was the result of mechanical constraints caused by the hyperplastic AER (Grüneberg 1960; Milaire 1967). However, recent work has established that the onset of interdigital cell death in the foot plate is concomitant with the cessation of AER function, and that local administration of fibroblast growth factors (FGFs) in the interdigital region of chick limb buds can inhibit interdigital cell death and cause the formation of soft-tissue syndactyly (Macias et al. 1996). This phenotype is strikingly similar to the phenotypes of the Jag2 ${ }^{\mathrm{DSSL}}$ and Jag2 ${ }^{\mathrm{sm}}$ mutants. We demonstrate here that in the Jag2 ${ }^{\triangle \mathrm{DSL}}$ homozygotes, Bmp2 and Bmp7 expression and interdigital cell death are reduced. Our model is that the hyperplastic AER of the Jag ${ }^{\Delta \mathrm{DSL}}$ (and Jag2 ${ }^{\mathrm{sm}}$ ) homozygotes produces excess FGF activity that inhibits expression of Bmp2 and Bmp7 in the foot plate, with a consequent reduction of interdigital cell death. The expansion of the Shh expression domain in the Jag $2^{\Delta \mathrm{DSL}}$ homozygotes (presumably via the positive feedback loop between the ZPA and the AER) supports our idea that the hyperplastic AER of the Jag2 ${ }^{\triangle \mathrm{DSL}}$ mutants produces excess FGF activity. A ntagonistic interactions between the FGF and BM P signal ing pathways have been reported previously for both limb and mandibular development (Niswander and Martin 1993; Neübuser et al. 1997). However, the altered morphology of the foot plate observed in the Jag2 ${ }^{\Delta \mathrm{DSL}}$ and Jag2 ${ }^{\mathrm{sm}}$ homozygotes most likely also contributes to the syndactylous phenotype, particularly the secondary osseous fusions of the distal phalanges.

Our model that excess FGF activity produced by the hyperplastic AER inhibits BMP expression in the limb mesenchyme and thus causes a reduction of interdigital cell death is consistent with the hypothesis that BMPs are important regulators of programmed cell death in the limb bud (e.g., Macias et al. 1996, 1997; Y okouchi et al. 1996; Zou and N iswander 1996; Dunn et al. 1997; Hof- 
man et al. 1997). However, given the gross morphological change of the AER and the expansion of the Fgf8 expression domain throughout the anterior-posterior axis of the Jag $2^{\triangle \mathrm{DSL}}$ mutant $\mathrm{AER}$, it is striking that only interdigital cell death, but not cell death in the anterior and posterior necrotic zones, are affected in the Jag2 $2^{\Delta \mathrm{DSL}}$ homozygotes. It has been shown that overexpression of a dominant-negative form of BM P2/4 receptor la in the chick limb inhibited programmed cell death in both the interdigital mesenchyme and the anterior and posterior necrotic zones (Yokouchi et al. 1996). This indicates that, at least in the chick, BMPs are regulators of programmed cell death in all regions of the limb mesenchyme. In Jag2 ${ }^{\Delta \mathrm{DSL}}$ mutant limb buds, both Bmp2 and Bmp7 are downregulated only in the interdigital regions, leaving the BMP-mediated apoptotic signaling pathway intact in the anterior and posterior necrotic zones. One possible explanation for the specific reduction of Bmp2/7 expression only in the interdigital region of the Jag2 ${ }^{\Delta \mathrm{DSL}}$ mutant limb bud might be an asymmetric distribution of a positive regulator(s) of Bmp2/7 transcription in the limb bud. If such a positive regulator were expressed at higher levels in the anterior and posterior regi ons of the limb mesenchyme, it could counteract the inhibitory FGF activity and result in unaltered expression of Bmp2 and Bmp7 in the anterior and posterior mesenchyme.

\section{Amorphic and hypomorphic alleles of Jag2}

The Jag $2^{\text {sm }}$ missense mutation changes an invariant glycine to serine at codon 267 in the first EGF repeat of the Jagged2 protein, which Sidow et al . (1997) suggest creates a hypomorphic Jag2 mutant allele. The more severe phenotype of the Jag2 ${ }^{\Delta \mathrm{DSL}}$ homozygotes supports the idea that Jag $2^{\text {sm }}$ is a hypomorphic allele, whereas Jag $2^{\Delta D S L}$ is an amorphic (null) allele. The limb phenotype of Jag2 ${ }^{\Delta \mathrm{DSL}}$ homozygotes, although similar to that of Jag2 ${ }^{\text {sm }}$ homozygotes, appears more severe. N either secondary osseous fusions of the forefeet nor terminal splitting of distal phalanges (both of which are present in Jag2 ${ }^{\Delta \mathrm{DSL}}$ homozygotes) were reported in Jag2 ${ }^{\mathrm{sm}}$ homozygotes (Grüneberg 1956, 1960). In addition, no Jag2 ${ }^{\mathrm{DSL}}$ homozygote has survived for more than a few hours after birth, whereas many Jag2 ${ }^{\text {sm }}$ homozygotes are viable. Although postnatal lethality was noted in the original description of the Jag2 ${ }^{\text {sm }}$ mutation (Grüneberg 1956), its cause was not determined. One obvious implication from our work is that the postnatal lethality originally described for the Jag2 ${ }^{\text {sm }}$ mutants may be caused by incompletely penetrant craniofacial defects, such as the cleft palate and tongue fusions observed in the Jag2 ${ }^{\Delta \mathrm{DSL}}$ homozygotes. Interestingly, a genome scan in mice for teratogen-induced cleft palate and cleft lip susceptibility loci identified several chromosomal regions associated with clefting susceptibility (Diehl and Erickson 1997). One of the identified regions maps to distal chromosome 12 and includes the map postition of the Jag2 gene. This result suggests Jag2 as a possible candi date gene invol ved in teratogen-induced clefting susceptibility in mice.
Recent results in the chick have suggested that Jag2 acts downstream of the Radical Fringe gene in regulating formation of the AER (Laufer et al. 1997; Rodriguez-Esteban et al. 1997). Whether this regulatory pathway is conserved in mice is open to question, because expression of the Radical Fringe gene cannot be detected in mouse limb buds by whole mount in situ hybridization (Johnston et al. 1997; N. Zhang and T. Gridl ey, unpubl.). Our results demonstrate that Jag2 is not required in mice for AER formation, and instead suggest that Jag2 may act to negatively regulate growth and function of the AER.

\section{Materials and methods}

Isolation of genomic and CDNA clones and targeting vector construction

To isolate mouse Jagged2 cDN A clones, the dBEST expressed sequence tag database was searched with the rat Jagged2 CDN A sequence (Shawber et al. 1996). The insert from one of the homologous EST clones identified in this search (dBEST no. 336371) was used as a probe to screen a mouse brain cDNA library. One clone isolated in this screen (CJ4a) had a 1.4-kb insert that exhibited $>85 \%$ nucleotide sequence identity to the rat Jagged2 cDNA (the mouse gene was given the symbol Jag2 by the International Committee on Standardized Genetic Nomenclature for Mice). The sequence of this partial CDN A clone has been submitted to GenBank (accession number AF010137). Genomic clones were isolated from a Lambda DASH-II mouse genomic library (Stratagene), with a 1.2-kb insert encoding part of the EGF repeat region of the rat Jagged $2 \mathrm{CDN} A$ as a probe. The genomic organization of a portion of the mouse Jag2 locus was determined by restriction enzyme mapping, blot hybridization, and nucleotide sequencing.

To construct the targeting vector, a $2.2-\mathrm{kb}$ Sacl fragment of the Jag2 gene was subcloned upstream of a PGK-neo expression cassette (Soriano et al. 1991), and a 4.0-kb Spel-N otl Jag2 fragment was subcloned downstream of the PGK-neo cassette. This resulted in the del etion of a 5.0-kb genomic fragment containing the exons encoding the DSL domain and half of the first EGF repeat of the Jagged2 protein. We refer to this al lele as Jag2 ${ }^{\Delta \mathrm{DSL}}$. An HSV-tk cassette (M ansour et al. 1988) was al so introduced to allow negative selection against random integration of the targeting vector.

Electroporation, selection and screening of ES cells, and mouse and embryo genotyping

CJ7 ES cells were el ectroporated with $25 \mu \mathrm{g}$ of linearized targeting vector, sel ected, screened, and injected into bl astocysts from C57BL/6J mice, and the resulting chimeras bred with C57BI / 6J femal es as described previously (Swiatek et al. 1994). Fl animals heterozygous for the Jag $2^{\Delta \mathrm{DSL}}$ allel e were intercrossed for analysis. Mice and embryos were genotyped by Southern blot analysis or by allele-specific PCR. PCR primers for the wild-type Jag2 allele were DSL1 (5'-ACTACAGTGCCACCTGCAAC-3') and DSL2 (5'-CTTCGTGGCCTACTAAAGCC-3'), giving a 374-bp amplification product. The primers for the Jag2 ${ }^{\Delta \mathrm{DSL}}$ allele were J2KO2 (5'-GCACGAGACTAGTGAGACGTG-3'), located in the neo cassette and J2KO3 (5'-GAGTGAGAGTGTTCATGCTGAG-3'), giving a 530-bp amplification product.

Histology and in situ hybridization

Embryos were dissected and DNA was prepared from the yolk sacs or tails for genotyping by PCR or by Southern blot analysis. 
Embryos for histological analysis were fixed in Bouin's fixative. Fixed embryos were dehydrated through graded alcohols, embedded in paraffin, sectioned at $6 \mu \mathrm{m}$, and stained with hematoxylin and eosin. Embryos for in situ hybridization were fixed overnight at $4^{\circ} \mathrm{C}$ in $4 \%$ paraformal dehyde in PBS. Whole mount in situ hybridization and hybridization of cryostat-sectioned embryos with nonradioactive probes were performed as described previously (Lindsell et al. 1996).

\section{Detection of apoptotic cell death and skeletal analyses}

A poptotic cell death in the AER of Jag2 ${ }^{\mathrm{DSSL}}$ homozygotes and littermate controls at E10.5 was assessed by TUNEL labeling. E10.5 embryos were fixed in 3.7\% paraformaldehyde in PBS overnight at $4^{\circ} \mathrm{C}$, embedded in paraffin, and sectioned. Apoptotic cells were detected by use of the A popT ag in situ apoptosis detection kit (Oncor, Gaithersburg, MD) following the manufacturer's instructions. Apoptotic cell death in limb buds at E13.5 was assessed by whole mount vital dye staining with Nile Blue sulfate (M ori et al. 1995). Embryos from Jag2 ${ }^{\Delta \mathrm{DSL}}$ heterozygous intercrosses were dissected and were stained in a 1:50,000 (wt/ vol) solution of N ile Blue sulfate (Fluka) in Hank's balanced salt solution for $60-90 \mathrm{~min}$ at $37^{\circ} \mathrm{C}$. After staining, limb buds were rinsed in PBS and photographed. Alizarin-redstained skel etal preparations were performed as described ( $\mathrm{M}$ artin et al. 1995).

\section{Flow cytometry}

Multicolor flow cytometric (FACScan, Becton Dickinson, Palo Alto, CA) analysis was used to compare T cell differentiation in fetal thymuses from Jag ${ }^{\Delta \mathrm{DSL}}$ homozygous mutant embryos and heterozygous and wild-type littermates. Single cell suspensions were prepared from thymuses of individual embryos at E18 and suspended at $2 \times 10^{7} / \mathrm{ml}$ in FACS buffer $\left(\mathrm{Ca}^{2+}\right.$ and $\mathrm{M} \mathrm{g}^{2+}$ free PBS containing $0.1 \%$ sodium azide with $2 \%$ FBS). Aliquots of $10^{6}$ thymocytes $(50 \mu \mathrm{l})$ were stained simultaneously with monoclonal antibodies specific for the $T$ cell differentiation markers CD4 and CD8. CD8 expression was detected with the monoclonal antibody 53-6.72 conjugated to a green fluorescent FITC tag. CD4 expression was detected with the biotin conjugated monoclonal antibody GK1.5 that was developed subsequently with a red fluorescent streptavidin-Red670 tag (Pharmingen, San Diego CA). Separate al iquots of thymocytes stained for both CD4 and CD8 expression were assessed respectively for the presence of rearranged T cell receptor (TCR) $\alpha \beta$ or $\gamma \delta$ complexes with the monocl onal antibodies H 57-597 and GL3 conjugated to a phycoerythrin (PE) tag, whose red fluoresence intensity could be readiliy distinguished from that of Red670. Viable cells, identified by their forward versus side scatter profiles, were analyzed for staining with the antibodies described by use of the Cell Quest 3.0 data reduction program. Data are presented as the mean $\% \pm$ S.E.M. of cells expressing the indicated array of differentiation markers.

\section{Acknowledgments}

We thank A. Sidow and E. Lander for communicating results prior to publication, C. Hicks and B. Griffeth for technical assistance, N. Zhang for hel $p$ with the phage library screening, B. Hogan, E. Robertson, and G. Martin for probes, and A. Gossler and T. O'Brien for comments on the manuscript. This work was supported by grants from the $\mathrm{N}$ ational Institutes of Health (N S36437, HD34883 to T.G.; NS31885 to G.W.; DK46266, DK51090, AI41469 to D.V.S.) and the M arch of Dimes Founda- tion (1-FY 97-0193 to T.G.; 5-FY 94-0757 to G.W.). R.J. was supported by a N ational Research Service Award postdoctoral fellowship. This work was also supported by training grants from the $\mathrm{N}$ ational Cancer Institute to The Jackson Laboratory (Y.L.) and UCLA (C.S.), and by a Core grant from the $\mathrm{N}$ ational $\mathrm{Cancer}$ Institute to The Jackson Laboratory.

The publication costs of this article were defrayed in part by payment of page charges. This article must therefore be hereby marked "advertisement" in accordance with 18 USC section 1734 solely to indicate this fact.

\section{References}

Artavanis-Tsakonas, S., K. Matsuno, and M.E. Fortini. 1995. N otch signaling. Science 268: 225-232.

Bettenhausen, B., M. Hrabe de Angelis, D. Simon, J.-L. Guenet, and A. Gossler. 1995. Transient and restricted expression during mouse embryogenesis of DII1, a murine gene closely related to Drosophila Delta. Development 121: 2407-2418.

Blaumueller, C.M., H. Qi, P. Zagouras, and S. Artavanis-T sakonas. 1997. Intracellular cl eavage of $\mathrm{N}$ otch leads to a heterodimeric receptor on the plasma membrane. Cell 90: 281-291.

Conlon, R.A., A.G. Reaume, and J. Rossant. 1995. Notch1 is required for the coordinate segmentation of somites. Development 121: 1533-1545.

Crossley, P.H., G. Monowada, C.A. MacArthur, and G.R. Martin. 1996. Roles for FGF8 in the induction, initiation, and maintenance of chick limb development. Cell 84: 127-136.

Diehl, S.R. and R.P. Erickson. 1997. Genome scan for teratogeninduced clefting susceptibility loci in the mouse: Evidence of both allelic and locus heterogeneity distinguishing cleft lip and cleft palate. Proc. Natl. Acad. Sci. 94: 5231-5236.

Dunn, N.R., G.E. Winnier, L.K. Hargett, J.J. Schrick, A.B. Fogo, and B.L.M. Hogan. 1997. Haploinsufficient phenotypes in Bmp4 heterozygous null mice and modification by mutations in Gli3 and Alx4. Dev. Biol. 188: 235-247.

Dunwoodie, S.L., D. Henrique, S.M. Harrison, and R.S.P. Beddington. 1997. Mouse DII3: A novel divergent Delta gene which may complement the function of other Delta homologues during early pattern formation in the mouse embryo. Development 124: 3065-3076.

Ellisen, L.W., J. Bird, D.C. West, A.L. Soreng, T.C. Reynolds, S.D. Smith, and J. Sklar. 1991. TAN-1, the human homolog of the Drosophila Notch gene, is broken by chromosomal translocations in T Iymphoblastic neoplasms. Cell 66: 649661.

Fallon, J.F., A. Lopez, M.A. Ros, M.P. Savage, B.B. Olwin, and B.K. Simandl. 1994. FGF-2: A pical ectodermal ridge growth signal for chick limb devel opment. Science 264: 104-107.

Ferguson, M.W.J. 1998. Palate development. Development (Suppl.) 103: 41-60.

Fortini, M.E. and S. Artavanis-T sakonas. 1994. The Suppressor of Hairless protein participates in $\mathrm{N}$ otch receptor signaling. Cell 79: 273-282.

Gridley, T. 1997. Notch signaling during vertebrate development and disease. Mol. Cell. Neurosci. 9: 103-108.

Grüneberg, H. 1956. Genetical studies on the skeleton of the mouse. XVIII. Three genes for syndactylism. J. Genet. 54: 113-145.

Grüneberg, H. 1960. Genetical studies on the skeleton of the mouse. XXV. The devel opment of syndactylism. Genet. Res. 1: $196-213$.

Henderson, S.T., D. Gao, E.J. Lambie, and J. Kimble. 1994. Iag-2 may encode a signaling ligand for the GLP-1 and LIN-12 receptors of C. elegans. Development 120: 2913-2924. 
Hofman, C., G. Luo, R. Balling, and G. Karsenty. 1996. Analysis of limb patterning in BMP-7-deficient mice. Dev. Genet. 19: 43-50.

Jarriault, S., C. Brou, F. Logeat, E.H. Schroeter, R. Kopan, and A. Israel. 1995. Signaling downstream of activated mammalian N otch. Nature 377: 355-358.

Johnson, R.L. and C.J. Tabin. 1997. Molecular models for vertebrate limb development. Cell 90: 979-990.

Johnston, S.H., C. Rauskolb, R. Wilson, B. Prabhakaran, K.D. Irvine, and T.F. Vogt. 1997. A family of mammalian Fringe genes implicated in boundary determination and the Notch pathway. Development 124: 2245-2254.

Joutel, A., C. Corpechot, A. Ducros, K. Vahedi, H. Chabriat, P. Mouton, S. Alamowitch, V. Domenga, M. Cécillion, E. Maréchal, J. Maciazek, C. Vayssiére, C. Cruaud, E.-A. Cabanis, M.M. Ruchoux, J. Weissenbach, J.F. Bach, M.G. Bousser, and E. Tournier-Lasserve. 1996. N otch3 mutations in CADASIL, a hereditary adult-onset condition causing stroke and dementia. Nature 383: 707-710.

Kaartinen, V., J.W. Voncken, C. Shuler, D. Warburton, D. Bu, N. Heisterkamp, and J. Groffen. 1995. A bnormal lung development and cleft palate in mice lacking TGF- $\beta$ b3 indicates defects of epithelial-mesenchymal interaction. Nature Genet. 11: 415-421.

Kopan, R., E.H. Schroeter, H. Weintraub, and J.S. Nye. 1996. Signal transduction by activated $\mathrm{mN}$ otch: Importance of proteolytic processing and its regulation by the extracellular domain. Proc. Natl. Acad. Sci. 93: 1683-1688.

Lan, Y., R. Jiang, C. Shawber, G. Weinmaster, and T. Gridley. 1997. The Jagged 2 gene maps to Chromosome 12 and is a candidate for the Igl and sm mutations. Mamm. Genome 8: 875-876.

Laufer, E., C.E. N elson, R.L. Johnson, B.A. Morgan, and C. Tabin. 1994. Sonic hedgehog and Fgf-4 act through a signaling cascade and feedback loop to integrate growth and patterning of the developing limb bud. Cell 79: 993-1003.

Laufer, E., R. Dahn, O.E. Orozco, C.-Y. Yeo, J. Pisenti, D. Henrique, U.K. A bbott, J.F. Fallon, and C. Tabin. 1997. Expression of Radical fringe in limb-bud ectoderm regulates apical ectodermal ridge formation. Nature 386: 366-373.

Li, L., I.D. Krantz, Y. Deng, A. Genin, A.B. Banta, C.C. Collins, M. Qi, B.J. Trask, W.L. Kuo, J. Cochran, T. Costa, M.E. Pierpont, E.B. Rand, D.A. Piccoli, L. Hood, and N.B. Spinner. 1997. Alagille syndrome is caused by mutations in human Jagged1, which encodes a ligand for N otch1. Nature Genet. 16: 243-251.

Lindsell, C.E., C.J. Shawber, J. Boulter, and G. Weinmaster. 1995. Jagged: A mammalian ligand that activates $\mathrm{N}$ otch1. Cell 80: 909-917.

Lohnes, D., M. Mark, C. Mendelsohn, P. Dollé, A. Dierich, P. Gorry, A. Gansmuller, and P. Chambon. 1994. Function of the retinoic acid receptors (RARs) during development. (I) Craniofacial and skeletal abnormalities in RAR double mutants. Development 120: 2723-2748.

Luo, B., J.C. Aster, R.P. Hasserjian, F. Kuo, and J. Sklar. 1997. Isolation and functional analysis of a CDNA for human Jagged2, a gene encoding a ligand for the $\mathrm{N}$ otch1 receptor. Mol. Cell. Biol. 17: 6057-6067.

Macias, D., Y. Gañan, M.A. Ros, and J.M. Hurle. 1996. In vivo inhibition of programmed cell death by local administration of FGF-2 and FGF-4 in the interdigital areas of the embryonic chick leg bud. Anat. Embryol. 193: 533-541.

Macias, D., Y. Gañan, T.K. Sampath, M .E. Piedra, M .A. Ros, and J.M. Hurle. 1997. Role of BM P-2 and OP-1 (BM P-7) in programmed cell death and skeletogenesis during chick limb development. Development 124: 1109-1117.
Mahmood, R., J. Bresnick, A. Hornbruch, C. Mahony, N. Morton, K. Colquhoun, P. Martin, A. Lumsden, C. Dickson, and I. Mason. 1995. A role for FGF-8 in the initiation and maintenance of vertebrate limb bud outgrowth. Curr. Biol. 5: 797-806.

Mansour, S.L., K.R. Thomas, and M.R. Capecchi. 1988. Disruption of the proto-oncogene int-2 in mouse embryo-derived stem cells: A general strategy for targeting mutations to nonselectable genes. Nature 336: 348-352.

Martin, J.F., A. Bradley, and E.N. OIson. 1995. The paired-like homeo box gene MHox is required for early events of skeletogenesis in multiple lineages. Genes \& Dev. 9: 1237-1249.

Matsuno, K., R.J. Diederich, M.J. Go, C.M. Blaumueller, and S. Artavanis-T sakonas. 1995. Deltex acts as a positive regulator of $\mathrm{N}$ otch signaling through interactions with the $\mathrm{N}$ otch ankyrin repeats. Development 121: 2633-2644.

Milaire, J. 1967. Histochemical observations on the developing foot of normal, oligosyndactylous $(\mathrm{Os} /+)$ and syndactylous (sm/sm) mouse embryos. Arch. Biol. (Liege) 78: 223-288.

Mo, R., A.M. Freer, D.L. Zinyk, M.A. Crackower, J. Michaud, H.H. Heng, K.W. Chik, X.-M. Shi, L.-C. Tsui, S.H. Cheng, A.L. Joyner, and C.-C. Hui. 1997. Specific and redundant functions of Gli2 and Gli3 zinc finger genes in skeletal patterning and development. Development 124: 113-123.

M ori, C., N. N akamura, S. Kimura, H. Irie, T. Takigawa, and K. Shiota. 1995. Programmed cell death in the interdigital tissue of the fetal mouse limb is apoptosis with DN A fragmentation. Anat. Rec. 242: 103-110.

Muskavitch, M.A. 1994. Delta-N otch signaling and Drosophila cell fate choice. Dev. Biol. 166: 415-430.

Myat, A., D. Henrique, D. Ish-Horowicz, and J. Lewis. 1996. A chick homologue of Serrate and its relationship with Notch and Delta homologues during central neurogenesis. Dev. Biol. 174: 233-247.

N eubüser, A., H. Peters, R. Balling, and G.R. Martin. 1997. Antagonistic interactions between FGF and BMP signaling pathways: A mechanism for positioning the sites of tooth formation. Cell 90: 247-255.

N iswander, L. and G.R. Martin. 1993. FGF-4 and BMP-2 have opposite effects on limb growth. Nature 361: 68-71.

N iswander, L., S. Jeffrey, G.R. M artin, and C. Tickle. 1994. Positive feedback loop coordinates growth and patterning in the vertebrate limb. Nature 371: 609-612.

O'Brien, T.P., D.L. M etallinos, H. Chen, M.K. Shin, and S.M. Tilghman. 1996. Complementation mapping of skeletal and central nervous system abnormalities in mice of the piebald deletion complex. Genetics 143: 447-461.

Oda, T., A.G. Elkahloun, B.L. Pike, K. Okajima, I.D. Krantz, A. Genin, D.A. Piccoli, P.S. Meltzer, N.B. Spinner, F.S. Collins, and S.C. Chandrasekharappa. 1997. Mutations in the human Jagged 1 gene are responsible for Alagille syndrome. Nature Genet. 16: 235-242.

Orioli, D., M. Henkemeyer, G. Lemke, R. Klein, and T. Pawson. 1996. Sek 4 and N uk receptors cooperate in guidance of commissural axons and in palate formation. EMBO J. 15: 60356049.

Pan, D. and G.M. Rubin. 1997. Kuzbanian controls proteolytic processing of $\mathrm{N}$ otch and mediates lateral inhibition during Drosophila and vertebrate neurogenesis. Cell 90: 271-280.

Proetzel, G., S.A. Pawlowski, M.V. Wiles, M. Yin, G.P. Boivin, P.N. Howles, J. Ding, M.W.J. Ferguson, and T. Doetschman. 1995. Transforming growth factor- $\beta 3$ is required for secondary palate fusion. Nature Genet. 11: 409-414.

Robey, E. 1997. Notch in vertebrates. Curr. Opin. Gen. Dev. 7: 551-557.

Robey, E., D. Chang, A. Itano, D. Cado, H. Alexander, D. Lans, 
G. Weinmaster, and P. Salmon. 1996. An activated form of $\mathrm{N}$ otch influences the choice between CD4 and CD8 T cell lineages. Cell 87: 483-492.

Rodriguez-Esteban, C., J.W. Schwabe, J. De La Peña, and J.C. Izpisúa-Belmonte. 1997. Radical fringe positions the apical ectodermal ridge at the dorsoventral boundary of the vertebrate limb. Nature 386: 360-366.

Satokata, I. and R. M aas. 1994. Msx1 deficient mice exhibit cleft palate and abnormalities of craniofacial and tooth development. Nature Genet. 6: 348-356.

Shawber, C., J. Boulter, C.E. Lindsell, and G. Weinmaster. 1996. Jagged2: A Serrate-like gene expressed during rat embryogenesis. Dev. Biol. 180: 370-376.

Sidow, A., M.S. Bulotsky, A.W. Kerrebrock, R.T. Bronson, M.J. Daly, M.P. Reeve, T.L. Hawkins, B.W. Birren, R. Jaenisch, and E.S. Lander. 1997. Serrate2 is disrupted in the mouse limb development mutant syndactylism. Nature 389: 722725.

Singh, G., D.M. Supp, C. Schreiner, J. McN eish, H.-J. Merker, N.G. Copeland, N.A. Jenkins, S.S. Potter, and W. Scott. 1991. legless insertional mutation: Morphological, molecular, and genetic characterization. Genes \& Dev. 5: $2245-2255$.

Soriano, P., C. Montgomery, R. Geske, and A. Bradley. 1991. Targeted disruption of the c-src proto-oncogene leads to osteopetrosis in mice. Cell 64: 693-702.

Swiatek, P.J., C.E. Lindsell, F. Franco del Amo, G. Weinmaster, and T. Gridley. 1994. Notch1 is essential for postimplantation development in mice. Genes \& Dev. 8: 707-719.

Vogel, A., C. Rodriguez, and J.C. Izpisúa-Belmonte. 1996. Involvement of FGF-8 in initiation, outgrowth and patterning of the vertebrate limb. Development 122: 1737-1750.

Washburn, T., E. Schweighoffer, T. Gridley, D. Chang, B.J. Fowlkes, D. Cado, and E. Robey. 1997. N otch activity influences the $\alpha \beta$ versus $\gamma \delta$ T cell lineage decision. Cell 88: 833843.

Weinmaster, G. 1997. The ins and outs of N otch signaling. Mol. Cell. Neurosci. 9: 91-102.

Yokouchi, Y., J.-i. Sakiyama, T. Kameda, H. Iba, A. Suzuki, N. Ueno, and A. Kuroiwa. 1996. BMP-2/-4 mediate programmed cell death in chicken limb buds. Development 122: 3725-3734.

Zou, H. and L. Niswander. 1996. Requirement for BMP signaling in interdigital apoptosis and scale formation. Science 272: 738-741. 


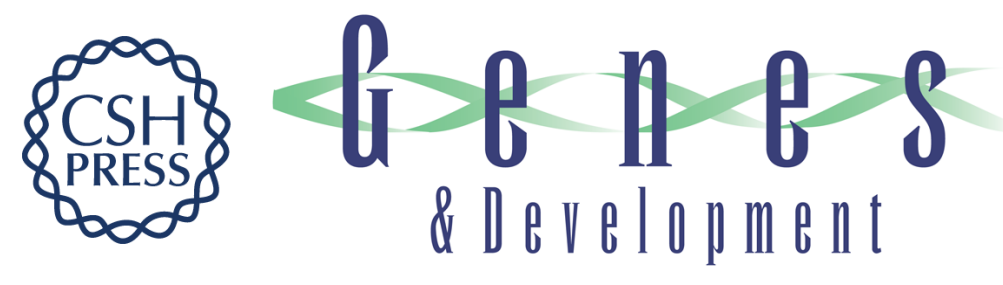

\section{Defects in limb, craniofacial, and thymic development in Jagged2 mutant mice}

Rulang Jiang, Yu Lan, Harry D. Chapman, et al.

Genes Dev. 1998, 12:

References This article cites 61 articles, 21 of which can be accessed free at: http://genesdev.cshlp.org/content/12/7/1046.full.html\#ref-list-1

License

Email Alerting

Receive free email alerts when new articles cite this article - sign up in the box at the top Service right corner of the article or click here.

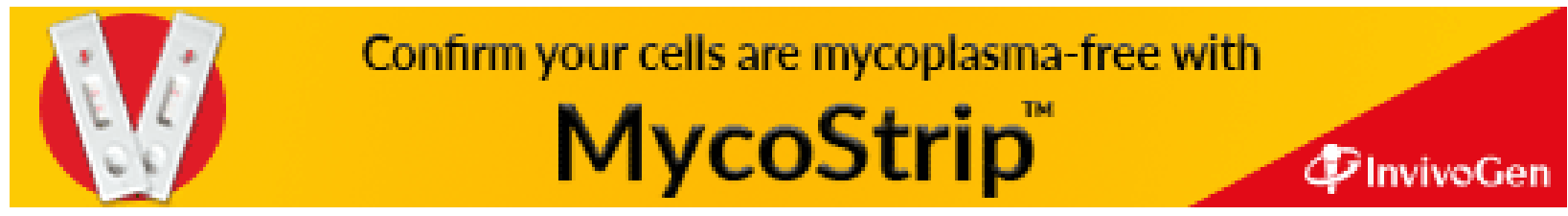

